Utah State University

DigitalCommons@USU

\title{
On the Extinction of Species in Jointly Determined Stochastic Systems
}

Amitrajeet A. Batabyal

Utah State University

Hamid Beladi

Follow this and additional works at: https://digitalcommons.usu.edu/eri

\section{Recommended Citation}

Batabyal, Amitrajeet A. and Beladi, Hamid, "On the Extinction of Species in Jointly Determined Stochastic Systems" (1999). Economic Research Institute Study Papers. Paper 173.

https://digitalcommons.usu.edu/eri/173

This Article is brought to you for free and open access by the Economics and Finance at DigitalCommons@USU. It has been accepted for inclusion in Economic Research Institute Study Papers by an authorized administrator of DigitalCommons@USU. For more information, please contact digitalcommons@usu.edu.

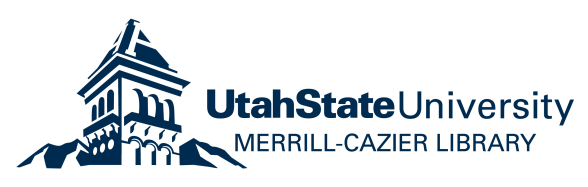


Economic Research Institute Study Paper

ERI \#99-23

\title{
ON THE EXTINCTION OF SPECIES IN JOINTLY \\ DETERMINED STOCHASTIC SYSTEMS
}

\author{
by \\ AMITRAJEET A. BATABYAL \\ Department of Economics \\ Utah State University \\ 3530 Old Main Hill \\ Logan, UT 84322-3530 \\ and \\ HAMID BELADI \\ Department of Economics and Finance \\ University of Dayton \\ 300 College Park \\ Dayton, OH 45469-2241
}

October 1999 
ON THE EXTINCTION OF SPECIES IN JOINTLY

DETERMINED STOCHASTIC SYSTEMS

\author{
Amitrajeet A. Batabyal, Associate Professor \\ Department of Economics \\ Utah State University \\ 3530 Old Main Hill \\ Logan, UT 84322-3530
}

Hamid Beladi

Department of Economics and Finance

University of Dayton

300 College Park

Dayton, OH 45469-2241

The analyses and views reported in this paper are those of the author(s). They are not necessarily endorsed by the Department of Economics or by Utah State University.

Utah State University is committed to the policy that all persons shall have equal access to its programs and employment without regard to race, color, creed, religion, national origin, sex, age, marital status, disability, public assistance status, veteran status, or sexual orientation.

Information on other titles in this series may be obtained from: Department of Economics, Utah State University, 3530 Old Main Hill, Logan, Utah 84322-3530.

Copyright (C) 1999 by Amitrajeet A. Batabyal and Hamid Beladi. All rights reserved. Readers may make verbatim copies of this document for noncommercial purposes by any means, provided that this copyright notice appears on all such copies. 


\title{
ON THE EXTINCTION OF SPECIES IN JOINTLY \\ DETERMINED STOCHASTIC SYSTEMS \\ Amitrajeet A. Batabyal and Hamid Beladi
}

\begin{abstract}
The sizeable literature on extinction in economics has paid scant attention to the problem of constructing measures of species extinction. Moreover, this literature has not studied the question of species extinction in stochastic systems that are jointly determined. Consequently, the objective of this paper is to use probability theory to construct a measure of species extinction in jointly determined ecological-economic systems.

JEL Classification: Q20, C44
\end{abstract}

Key words: ecological economic system, species extinction 


\section{ON THE EXTINCTION OF SPECIES IN JOINTLY DETERMINED STOCHASTIC SYSTEMS ${ }^{1}$}

\section{Introduction}

Beginning with the seminal work of Clark (1973a; 1973b), there now exists a sizeable literature in economics on the extinction of species. ${ }^{2}$ Generally speaking, this literature has focused on two related issues. The first issue concerns the effects of alternate forms of property rights on the possibility of extinction. The second issue relates to the conditions under which extinction is socially optimal. Although these are important issues in the economics of extinction, it is now clear that the question of species extinction has an ecological and an economic component to it. Consequently, as Swanson (1994) and others have noted, to understand extinction it is necessary to understand the effects that economic activities and environmental factors have on species in ecological economic systems (ecosystems) that are jointly determined.

Once this basic fact is recognized, a whole host of research questions regarding the extinction of species present themselves. ${ }^{3}$ In this paper, we shall focus on one of these questions that has not been analyzed previously in the economics literature. The question of interest is the following: Can one formally quantify the effects that economic activities and environmental factors have on the likelihood that an arbitrary species in an ecosystem will go extinct? Put differently, can one construct a measure of extinction that incorporates in it the effects that economic activities and

${ }^{1}$ Batabyal acknowledges financial support from the Utah Agricultural Experiment Station, Utah State University, Logan, UT 84322-4810, by way of grant UTA 024. Approved as journal paper \#7070. The usual disclaimer applies.

${ }^{2}$ For more on this literature, see Berck (1979), Hartwick (1982), Cropper (1988), Clark (1990), and Swanson

${ }^{3}$ Many of these questions are discussed in Soule and Kohm (1989). 
environmental factors have on species? In this paper, we use probability theory to demonstrate that the answer to the above question is yes.

The rest of this paper is organized as follows. Section 2 a provides a formal model of a stochastic ecosystem. Section $2 \mathrm{~b}$ describes the construction of a measure of species extinction. Section $2 \mathrm{c}$ discusses the properties of this measure and suggests ways of operationalizing it. Finally, section 3 concludes and offers suggestions for future research.

\section{Species Extinction in a Stochastic Ecosystem}

\section{2a. Preliminaries}

Consider a stochastic ecosystem that consists of a finite number of species. Let us focus on an arbitrary—say the $i^{t h}$ — species in this ecosystem. Suppose that the $i^{\text {th }}$ species has $n$ individual members. Economic activities such as grazing and hunting, and environmental factors, such as droughts and hurricanes result in random shocks to the individual members of the $i^{\text {th }}$ species. While these shocks are, in general, detrimental to the various members of the species, they need not have the same impact on all the members. Suppose that these shocks are independent, and that they are drawn from a distribution function $F(\cdot) .{ }^{4}$ Shocks can be of various magnitudes and the reader should think of higher magnitude shocks as being more damaging to the individual members of the $i^{\text {th }}$ species. In particular, if a shock of magnitude $z$ occurs at time $t$, then every member of the $i^{t h}$ species that was alive at $\boldsymbol{t}$ will, independently, perish with probability $\boldsymbol{z}$.

${ }^{4}$ Ideally, we would like to separate the shocks that result from economic activities from those that result from environmental factors. However, if we work with two distribution functions, then the task of constructing a closed form measure of species extinction becomes intractable. 
We now need to link these shocks to the extinction of the $i^{\text {th }}$ species. In this connection, we first note that in general "it is not one single disturbance that causes species extinction...but rather the cumulative effects of many different disturbances" (Soule and Kohm, 1989, p. 16, emphasis added). Consequently, let us define $S$ to be the number of shocks that are required for all the individual members to perish, i.e., for the $i^{\text {th }}$ species to become extinct. ${ }^{5}$ Our task now is twofold. First, following Ross (1993, pp. 23-24; 1996, pp. 31-32) we shall compute $\operatorname{Prob}\{S \leq d\}$, the distribution function of $S$. We shall then use this function to determine $E[S]$, the expected number of shocks that will ensure the extinction of the $i^{t h}$ species. $E[S]$ is our measure of species extinction. However, before we undertake these two tasks, let us briefly comment on two papers in the ecology literature that are related to the objective of this paper.

Solow (1993) discusses two statistical techniques for inferring species extinction from sighting data. Solow does not discuss the role of economic activities in causing the extinction of species. Further, his analysis depends on the assumption that prior to extinction, sightings follow a stationary Poisson process. More recently, Reed (1996) has presented a method for assessing the certainty of species extinction using statistical probability. Here too, there is no mention of the role of economic activities in causing species extinction; moreover, Reed's analysis depends on the assumption that when a particular site is surveyed, "a reasonable effort" has been made to detect the target species. In contrast with these two papers, this paper's measure of extinction (i) explicitly accounts for the role of economic activities in causing species extinction, and (ii) does not make any distributional or ad hoc assumptions.

\footnotetext{
${ }^{5}$ The reader will note that this definition of $S$ is consistent with the view that "[e]xtinction consists of ... the population size . . going to zero." (Soule and Kohm, 1989, p. 32). However, variations on this view are clearly possible. For instance, species whose growth exhibits critical depensation will have a minimum viable population level. Below this level, even though all species members are not dead, the ultimate extinction of the species is certain. For more on this, see Clark (1990, pp. 17-20).
} 


\section{2b. A Measure of Species Extinction}

Rather than compute $\operatorname{Prob}\{S \leq d\}$ directly, let us first compute $\operatorname{Prob}\{S>d\}$. To this end, let $A_{j}, j=1, \ldots, n$, denote the event that the $j^{\text {th }}$ member of the $i^{\text {th }}$ species has survived the first $d$ shocks from the occurrence of environmental events and the continuance of economic activities. Then it follows that

$$
\operatorname{Prob}\{S>d\}=\operatorname{Prob}\left\{\bigcup_{j=1}^{j=n} A_{j}\right\}
$$

The RHS of equation (1) can be simplified further. This simplification yields

$$
\operatorname{Prob}\{S>d\}=\sum_{j=1}^{j=n} A_{j}-\sum_{j} \sum_{<k} \operatorname{Prob}\left\{A_{f} A_{k}\right\}+\ldots+(-1)^{1+n} \operatorname{Prob}\left\{A_{1} A_{2} \ldots A_{n}\right\} .
$$

To determine the above probability, let $p_{m}$ be the probability that a set of $m$ members of species $\boldsymbol{i}, \mathbf{1} \leq \boldsymbol{m} \leq \boldsymbol{n}$, will survive some exogenous shock. Then, by conditioning on the magnitude of this shock, we get

$$
p_{m}=\int(1-z)^{m} d F(z)
$$

Now recall that $\operatorname{Prob}\left\{A_{j}\right\}$ is the probability that the $j^{\text {th }}$ species member has survived the first $d$ shocks. Then by independence, it follows that

$$
\operatorname{Prob}\left\{A_{j}\right\}=p_{1}^{d}, \operatorname{Prob}\left\{A_{f} A_{k}\right\}=p_{2}^{d}, \operatorname{Prob}\left\{A_{1}, \ldots, A_{n}\right\}=p_{n}^{d} .
$$

Using the result of equation (4) in equation (2), we get

$$
\operatorname{Prob}\{S>d\}=\left(\begin{array}{l}
n \\
1
\end{array}\right) p_{1}^{d}-\left(\begin{array}{l}
n \\
2
\end{array}\right) p_{2}{ }^{d}+\left(\begin{array}{l}
n \\
3
\end{array}\right) p_{3}{ }^{d} \ldots(-1)^{1+n}\left(\begin{array}{l}
n \\
n
\end{array}\right) p_{n}{ }^{d} .
$$

We know that $\operatorname{Prob}\{S \leq d\}=1-\operatorname{Prob}\{S>d\}$. Using this in equation (5) gives

$$
\operatorname{Prob}\{S \leq d\}=1-n p_{1}^{d}+\left(\begin{array}{l}
n \\
2
\end{array}\right) p_{2}^{d}-\left(\begin{array}{l}
n \\
3
\end{array}\right) p_{3}^{d} \cdots-(-1)^{1+n} p_{n}^{d}
$$


Equation (6) gives us a closed form expression for the distribution of $S$, the total number of shocks that are required for the $i^{\text {th }}$ species of our ecosystem to become extinct. This distribution function gives us an indication of the ability of the $i^{\text {th }}$ species to withstand exogenous economic and environmental disturbances. Now, to obtain our measure of species extinction, we will need to compute the mean of $S$.

Note that $S$ is a nonnegative, integer valued, random variable. This tells us that the expected value of $S$ is given by

$$
E[S]=\sum_{d=0}^{\infty} \operatorname{Prob}\{S>d\}
$$

The probability on the RHS of equation (7) is given in equation (5). Using this in equation (7) and then performing some algebraic manipulations, we get an expression for the mean of $S$. That expression is

$$
E[S]=\sum_{j=1}^{n}\left(\begin{array}{l}
n \\
j
\end{array}\right) \frac{(-1)^{1+j}}{1-p_{j}}
$$

\section{2c. Discussion}

The expression in equation (8) is our stochastic measure of species extinction. We see that this measure-which we have computed for an ecological-economic system-depends on two things. First, the size of the population of the $i^{\text {th }}$ species, $(n)$, is a determinant of $E[S]$. This result is consistent with previous findings in the ecology literature. Indeed, the ecology literature has demonstrated the "overwhelming importance of population size in determining how long a [species] will survive..." (Pimm, 1991, p. 137). Second, $E[S]$ also depends on the probability $\left(p_{j}\right)$ that a given set of individuals in the population of the ith species will survive exogenous shocks. This result is related to the notion of the "risk of extinction" from the ecology literature (see Pimm et al., 1988). 
Thus we see that although the introduction of economic activities and environmental factors into the study of species extinction gives rise to some new concepts, these concepts are related to extant findings in the ecology literature. Let us now briefly discuss ways in which this paper's measure of species extinction might be operationalized.

There are many methods that can be used to determine the size of the population (n). For a number of species - examples include barnacles, the northern fur seal, and territorial birds - it is possible to actually count the total number of individuals living in a particular area of interest. For other species, sampling methods and the capture/recapture method can be used to determine the size of the population. ${ }^{6}$ The computation of the survival probabilities $\left(p_{j}^{\prime} s\right)$ is likely to be more difficult. However, it seems to us that it should be possible to adapt and use two existing techniques to compute these probabilities. The first technique is the one that Pimm et al. (1988) have used to compute the "risk of extinction" of a particular species. The second technique involves the use of stochastic population models to compute these survival probabilities (see Krebs, 1985, pp. 228-232). In this way, once $(n)$ and the $\left(p_{j}^{\prime} s\right)$ have been determined, it will be possible to operationalize this paper's measure of species extinction.

${ }^{6}$ For more on the use of these techniques, see Krebs (1985, pp. 160-165). 


\section{Conclusions}

In this paper we showed how the effects of economic activities and environmental factors can be modeled tractably to construct a measure of species extinction in jointly determined ecological-economic systems. We commented on the properties of this measure and then discussed ways in which this measure might be operationalized.

The analysis of this paper can be extended in a number of different directions. In what follows, we suggest two possible extensions. First, it would be worthwhile to determine whether our conjecture - see footnote 4-that in constructing closed form measures of species extinction, it is not possible to separate the effects of economic activities from those of environmental factors, is, in fact, true. Second, it would be useful to study the extent to which interdependencies between species dampen or exacerbate the effects of shocks on the individual members of a particular species. Formal studies of extinction which incorporate these aspects of the problem into the analysis will enable us to have a better understanding of the effects of economic activities and environmental factors on the species that reside in jointly determined ecological-economic systems. 


\section{References}

Berck, P. 1979. Open Access and Extinction. Econometrica 47:877-82.

Clark, C. W. 1973a. The Economics of Overexploitation. .Science 181:630-4.

Clark, C. W. 1973b. Profit Maximization and the Extinction of Animal Species. Journal of Political Economy 81:950-61.

Clark, C. W. 1990. Mathematical Bioeconomics, $2^{\text {nd }}$ ed. New York, NY: Wiley.

Cropper, M. L. 1988. A Note on the Extinction of Renewable Resources. Journal of Environmental Economics and Management 15:64-70.

Hartwick, J. M. 1982. Free Access and the Dynamics of the Fishery. In L. J. Mirman and D. F. Spulber (eds.), Essays in the Economics of Renewable Resources, Amsterdam, The Netherlands: North-Holland.

Krebs, C. J. 1985. Ecology, $3^{\text {rd }}$ ed. New York, NY: Harper and Row.

Pimm, S. L., Jones, H. L., and Diamond, J. 1988. On the Risk of Extinction. American Naturalist 132:757-85.

Pimm, S. L. 1991. The Balance of Nature? Chicago, IL: University of Chicago Press.

Reed, J. M. 1996. Using Statistical Probability to Increase Confidence of Inferring Species Extinction. Conservation Biology 10:1283-5.

Ross, S. M. 1993. Introduction to Probability Models, $5^{\text {th }}$ ed. San Diego, CA: Academic Press.

Ross, S. M. 1996. Stochastic Processes, $2^{\text {nd }}$ ed. New York, NY: Wiley.

Solow, A. R. 1993. Inferring Extinction from Sighting Data. Ecology 74:962-4.

Soule, M. E., and Kohm, K. A. (eds.). 1989. Research Priorities for Conservation Biology. Washington, D.C.: Island Press.

Swanson, T. M. 1994. The Economics of Extinction Revisited and Revised, Oxford Economic Papers 46:800-21. 